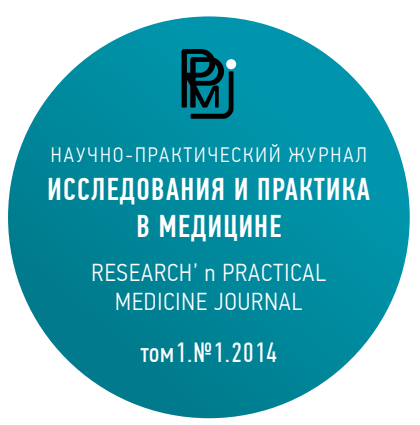

Ключевые слова:

немелкоклеточный рак легкого, хирургическое и комбинированное лечение, факторы прогноза Keywords:

non-small cell lung cancer, surgical and combined treatment, prognostic factors
Для корреспонденции:

Колбанов Константин Иванович, доктор медицинских наук, старший научный сотрудник торакального отделения отдела торакоабдоминальной онкохирургии МНИОИ им. П. А. Герцена - филиал ФГБУ «ФМИЦ им. П. А. Герцена» Минздрава России

Адрес: 125284, Российская Федерация, Москва,

2-й Боткинский проезд, д. 3.

Телефон: +7 (916) 503-29-05,

e-mail: kolbanovf@yandex.ru

Статья поступила 15.11.2014

Принята к печати 12.12.2014

For correspondence:

Kolbanov Konstantin Ivanovich,

MD, senior researcher of thoracic department of thoracoabdominal division Moscow Oncology Institute of the Hertsen FMRC MH RF

3, 2 Botkinskiy proezd, 125284

Russian Federation, Moscow

Tel: +7 (916) 503-29-05

e-mail: kolbanovf@yandex.ru

\section{ХИРУРГИЧЕСКОЕ ЛЕЧЕНИЕ БОЛЬНЫХ РЕЗЕКТАБЕЛЬНЫМ НЕМЕЛКОКЛЕТОЧНЫМ РАКОМ ЛЕГКОГО}

\author{
Колбанов К.И., Трахтенберг А.Х., Пикин О.В., Рябов А.Б., Глушко В.А.
}

МНИОИ им. П.А.Герцена - филиал ФГБУ «ФМИЦ им. П.А.Герцена» Минздрава России

(Москва, Российская Федерация)

125284, Российская Федерация, Москва, 2-ой Боткинский проезд, дом 3

\section{Резюме:}

Цель исследования. Изучение отдаленных результатов лечения больных резектабельным немелкоклеточным раком легкого с использованием хирургического метода позволило уточнить факторы прогноза.

Материалы и методы. Проведен анализ хирургического и комбинированного лечения 1420 больных немелкоклеточным раком легкого. У 42,7\% пациентов регионарные метастазы не выявлены, у 28,1\% - имелось поражение внутрилегочных и/или корневых узлов (N1), а у $28,9 \%$ - средостенных (N2). Радикальные операции выполнены 92,8\% больным. Послеоперационные осложнения диагностированы у $22,2 \%$. Летальность $-3,0 \%$.

Основные результаты. Общая пятилетняя выживаемость больных после радикального лечения составила $42,0 \pm 1,6 \%$, паллиативного $-19,8 \pm 3,3 \%$. При радикальном лечении более 5 лет пережили $65,0 \pm 3,6 \%$ больных IА стадии, $54,5 \pm 3,4 \%-I B, 49,0 \pm 5,2 \%-I I A, 40,8 \pm 4,0 \%$ - IIB, 18,8 2 2,5\% - IIIA и $13,4 \pm 5,8 \%$ - IIIB. У больных с N0 отдаленные результаты лечения были выше при плоскоклеточном раке $(62,1 \pm 3,5 \%)$, чем аденогенном $(52,5 \pm 4,6 \% p=0,048)$ и крупноклеточном $(45,5 \pm 7,7 \%, p=0,008)$ и в целом составили $58,4 \pm 2,4 \%$. Показатели пятилетней выживаемости после радикального комбинированного лечения у больных при N+ были ниже $(30,9 \pm 2,3 \%)$ и зависели от уровня поражения узлов (N1 или N2), заинтересованности зон средостения, морфологической структуры опухоли, а также объема операции.

Заключение. Радикальное хирургическое и комбинированное лечение (с послеоперационной лучевой терапией) может быть проведено большинству больных резектабельным немелкоклеточным раком легкого с удовлетворительными отдаленными результатами. Основными факторами прогноза следует считать характер лечения, стадию заболевания, особенно состояние регионарных внутригрудных лимфатических узлов. К дополнительным неблагоприятным прогностическим факторам у больных при NO относится аденогенный и крупноклеточный морфологический тип рака, при N1 - величинf опухоли Т4 и крупноклеточный рак, а N2 - метастазы в нескольких или всех зонах средостения и объеме операции билобэктомия.

\section{SURGICAL TREATMENT OF PATIENTS WITH RESECTABLE NON SMALL CELL LUNG CANCER}

\author{
Kolbanov K.I., Trakhtenberg A.Kh., Pikin O.V., Glushko V.A., Ryabov A.B. \\ Moscow Oncology Institute of the Hertsen FMRC MH RF (Moscow, Russian Federation) \\ 3, 2 Botkinskiy proezd, 125284, Russian Federation, Moscow
}

\section{Abstract:}

Objective. Study based on long-term results of treatment of patients with resectable non-small cell lung cancer using surgical method specified prognostic factors.

Materials and methods. The analysis of surgical and multimodal treatment in 1420 patients with NSCLC. In $42.7 \%$ of patients metastases in the lymph nodes were absent in $28.1 \%$ revealed bronchopulmonary defeat and root nodes (N1), 
while $28.9 \%$ - mediastinal (N2). Radical surgery performed $92.8 \%$ of patients. Postoperative complications were diagnosed in $22.2 \%$. The case fatality rate $-3.0 \%$.

Results. The overall five-year survival of patients after radical treatment was $42,0 \pm 1,6 \%$, palliative $-19,8 \pm$ $3,3 \%$. When radical treatment for more than 5 years experienced a $65,0 \pm 3,6 \%$ of patients with stage IA, 54,5 $\pm 3,4 \%-\mathrm{IB}, 49,0 \pm 5,2 \%-\mathrm{IIA}, 40,8 \pm 4,0 \%-\mathrm{IIB}, 18,8 \pm$ $2,5 \%$ - IIIA and $13,4 \pm 5,8 \%$ - IIIB. In patients with NO long-term results of treatment amounted to $58,4 \pm 2,4 \%$, were higher in squamous cell carcinoma $(62,1 \pm 3,5 \%)$, than adenocarcinoma $(52,5 \pm 4,6 \% p=0.048)$ and largecancer $(45,5 \pm 7,7 \%, p=0.008)$. Indicators of five-year survival after radical combined treatment in patients with $\mathrm{N}+$ were lower $(30,9 \pm 2,3 \%)$ and depended on the level of the lesion nodes (N1 or N2), interest areas of the mediastinum, the morphological structure of the tumor, as well as the volume of transactions.

Conclusions. Radical surgical and combined treatment (with postoperative radiotherapy) can be carried out by most of the patients with resectable non-small cell lung cancer with satisfactory long-term results. The main prognostic factors should be considered the type of the treatment, stage of disease, especially the state of regional hilar lymph nodes. Additional adverse prognostic factor in patients with NO is adenogenous and macrocellular morphological type of cancer, at N1 - T4 tumors and macrocellular carcinoma, and N2 - Metastasis in some or all areas of the mediastinum and the volume of surgery bilobectomy.

\section{Введение}

Рак лёгкого - наиболее распространённое в мировой популяции злокачественное новообразование.

По данным статистических отчетов за 2013 год в России зарегистрированы 56051 больных с впервые выявленной злокачественной опухолью трахеи, бронхов и легких. Среди мужчин, страдающих злокачественными опухолями различных локализаций, данная патология составила $18,4 \%$, а среди женщин - 3,8\%. Удельный вес пациентов с I стадией заболевания составил $11,1 \%$, со II - 14,5\%, III - 31,5\% и IV - 39,4\%. Противоопухолевое радикальное лечение в отчетном году завершено у 12926 (23,0\%) больных, из них хирургический метод применен у 53,1\% пациентов, комбинированный и комплексный - у 41,0\%, химиолучевой - у 5,9\% [1].

Общепризнанным, стандартизированным методом лечения больных с резектабельными формами немелкоклеточного рака легкого (НМРЛ), дающим реальные перспективы излечения, является хирургический [2,3]. Использование консервативных методов противоопухолевого лечения в комбинации с радикальной операцией улучшает отдаленные результаты при местно-распространенных стадиях заболевания $[4,5,6,7]$.

Общероссийских статистических показателей выживаемости больных раком легкого с учетом метода лечения или стадии заболевания нет. В целом более 5 лет переживают 39,3\% больных от числа стоящих на учете в конце года анализируемого периода [1].

Имеющиеся научные публикации отдельных центров по оказанию специализированной и высокотехнологичной онкологической помощи позволяют судить об эффективности применяемых методов лечения в отдельно взятых учреждениях или географических регионах. К факторам, влияющим на прогноз лечения, принято относить морфологический тип опухоли, ее размер, состояние регионарных лимфатических узлов, наличие гематогенных метастазов.

По данным РОНЦ им. Н.Н. Блохина, на отдаленные результаты лечения 2365 радикально оперированных больных НМРЛ достоверно влияли степень радикальности вмешательства, дифференцировка плоскоклеточного рака и возраст пациентов. Основным фактором прогноза остается распространенность опухолевого процесса: пятилетняя выживаемость пациентов с I стадией заболевания составила 48,8\%, со II - 32,4\% и III -21,0\% [8]

Применение послеоперационной лучевой терапий у 2464 больных НМРЛ с метастазами во внутригрудных лимфатических узлах существенно не повлияло на отдаленные результаты. Полученные показатели лечения в РНЦ Рентгенорадиологии свидетельствуют о лучшей выживаемости больных при поражении узлов группы N1 $(39,8 \%)$, нежели N2 (5,5\%) [9].

\section{Цель исследования}

Оценить отдаленные результаты лечения больных резектабельным немелкоклеточным раком легкого с использованием хирургического метода. Уточнить значимые факторы прогноза.

\section{Материалы и методы}

В анализ включено 1420 больных немелкоклеточным раком легкого, оперированных в МНИОИ им П.А. Герцена с 1980 по 2008 гг. (пробные торакотомии не учитывали). Бо́льшую часть оперированных составили мужчины $(89,8 \%)$, средний возраст которых 59 лет. Опухоль одинаково часто локализовалась в правом и левом легком: у $720(50,7 \%)$ и у 700 (49,3\%) больных соответственно. В целом чаще $(55,6 \%)$ диагностировали периферическую клинико-анатомическую форму опухоли, которая преобладала среди пациентов с относительно ранними стадиями $(66,7 \%)$ заболевания, у женщин $(87,1 \%)$. По данным послеоперационного гистологического исследования у 607 (42,7\%) пациентов метастазы во внутригрудных лимфатических узлах отсутствовали, у 399 (28,1\%) было поражены только внутрилегочные и/или корневые, а у $411(28,9 \%)$ - средостенные (табл. 1.).

В соответствии с Международной гистологической классификации (2004 г) у 63,7\% больных опухоль легкого была представлена плоскоклеточным, у 23,7\% - аденогенным, у 7,3\% - крупноклеточным, у 3,6\% - диморфным (адено-плоскоклеточным) и у 1,7\% - редкими формами рака бронхиальных желез (мукоэпидермоидный и аденокистозный). 
Радикальные операции выполнены у 1318 (92,8\%) больных. Комбинированный характер вмешательства потребовался 503 (35,4\%) больным: резекцию соседних структур и органов осуществляли чаще при пневмонэктомии (48,0\%), чем при лоб/билобэктоми (27,7\%). Всем больным обязательно выполняли медиастинальную лимфаденэктомию.

Послеоперационные осложнения диагностированы у 315 (22,2\%) больных, у части из них имелось сочетание нескольких. Летальность составила 3,0\%.

Статистический анализ данных был нами проведен с помощью программы SPSS, версия 19 (USA).

При отсутствии метастазов в регионарных лимфатических узлах (NO) и радикальной операции (RO) дополнительное противоопухолевое лечение не проводили ( $n=559)$.

Показанием к комбинированному лечению, как и большинство исследователей, несмотря на радикальный характер операции, считали наличие метастазов во внутригрудных лимфатических узлах (N1, N2). В качестве второго этапа лечения применяли дистанционную лучевую терапию с дневным дроблением дозы до СОД 46 Гр.

С учетом послеоперационной летальности, возникших осложнений и общего неудовлетворительного состояния отдельных пациентов план комбинированного лечения был реализован у 608 радикально оперированных. у 334 из них метастазы локализовались только во вну- трилегочных и/или корневых лимфатических узлах (N1), а у 274 - в средостенных (N2).

Таким образом, радикальное лечение выполнено у 1167 (82,2\%), паллиативное - у 210 пациентов. В последней группе 64 (30,5\%) больным после паллиативных операций проведена лучевая терапия по радикальной программе на остаточную (край резекции, неудаленные лимфатические узлы) опухоль.

\section{Результаты исследования}

В целом общая выживаемость больных после радикального лечения составила (n=1167) составила $42,0 \pm 1,6 \%$, паллиативного $(n=210)-19,8 \pm 3,3 \%$.

Стадия заболевания на сегодняшний день остается основным прогностическим фактором радикального лечения. Общая 5-летняя выживаемость больных

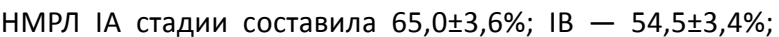

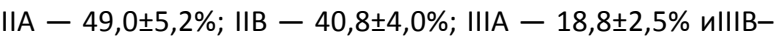
$13,4 \pm 5,8 \%$ (рис. 1 ).

Статистически значимое снижение показателей по отношению к ІА стадии наблюдается при ІІА ( $p=0,017$, $\mathrm{OP}=1,549$, 95\%ДИ 1,080-2,221), IIB ( $p=0,001, O P=1,673$, 95\%ДИ 1,242-2,252), IIIA ( $<<0,001$, OP=3,809, 95\%ДИ 2,934-4,945), IIIB ( $p<0,001$, ОР=4,511, 95\%ДИ 3,053-6.844).

Общая пятилетняя выживаемость больных НМРЛ при отсутствии метастазов в лимфатических узлах (Т1-

Таблица 1

Характеристика больных НМРЛ с учетом стадии* и клинико-анатомической формы заболевания (*Международная классификация по системе TNM , 2002г).

\begin{tabular}{|c|c|c|c|}
\hline \multirow{3}{*}{ Стадия } & \multicolumn{3}{|c|}{ Число больных } \\
\hline & \multirow[t]{2}{*}{ Абс. число, (\%) } & \multicolumn{2}{|c|}{ Клинико-анатомическая форма } \\
\hline & & Центральная & Периферическая \\
\hline І стадия & $550(38,7)$ & $183(33,3)$ & $367(66,7)$ \\
\hline IA - T1NOMO & 258 & 108 & 150 \\
\hline IB - T2NOMO & 292 & 75 & 217 \\
\hline II стадия & $377(26,6)$ & $202(53,6)$ & $175(46,4)$ \\
\hline IIA - T1N1M0 & 114 & 86 & 28 \\
\hline IIB & 263 & 116 & 147 \\
\hline - T2N1M0 & 216 & 96 & 120 \\
\hline - T3NOMO & 47 & 20 & 27 \\
\hline III стадия & $493(34,7)$ & $245(49,7)$ & $248(50,3)$ \\
\hline IIIA & 423 & 204 & 219 \\
\hline$-\mathrm{T} 1 \mathrm{~N} 2 \mathrm{MO}$ & 83 & 54 & 29 \\
\hline$-\mathrm{T} 2 \mathrm{~N} 2 \mathrm{MO}$ & 225 & 75 & 150 \\
\hline$-\mathrm{T} 3 \mathrm{~N} 1 \mathrm{M} 0$ & 47 & 38 & 9 \\
\hline$-\mathrm{T} 3 \mathrm{~N} 2 \mathrm{MO}$ & 68 & 37 & 31 \\
\hline IIIB & 70 & 41 & 29 \\
\hline -T4NOMO & 11 & 3 & 8 \\
\hline$-\mathrm{T} 4 \mathrm{~N} 1 \mathrm{M} 0$ & 23 & 16 & 7 \\
\hline$-\mathrm{T} 4 \mathrm{~N} 2 \mathrm{MO}$ & 36 & 22 & 14 \\
\hline ВСЕГО & $1420(100)$ & $630(44,4)$ & $790(55,6)$ \\
\hline
\end{tabular}


4NO MO) после радикального хирургического лечения

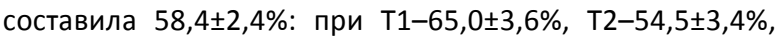
T3-51,5 $\pm 9,2 \%, \mathrm{~T} 4-42,9 \pm 22,4 \%$. Несмотря на имеющиеся статистически достоверные различия $(\mathrm{t} \geq 1,95)$ показателей при T1NOMO и T2NOMO многофакторный анализ не подтвердил данную зависимость. Однако, в ходе углубленного логистического анализа этих групп больных с учетом клинико-анатомической формы было установлено достоверное влияние критерия Т на отдаленные результаты у больных периферическим раком: более

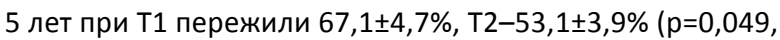
$\mathrm{OP}=1,468,95 \% Д И$ 1,002-2,153) больных. Показатели при центральном раке были недостоверны - 62,2 $\pm 5,6 \%$ и $58,6 \pm 7,0 \%$ ( $p=0,968$, OP=1,011, 95\%ДИ 0,577-1,772) соответственно. Полученные различия зависимостей могут быть обусловлены большей неоднородностью пациентов по размеру периферического очага Т2 (более $3 \mathrm{~cm}$, т.е. и более 10 см. по использованной классификации), чем уровню поражения бронха.

С учетом гистологического типа рака показатели пятилетней выживаемости у больных с N0 были в целом выше при плоскоклеточном раке $(62,1 \pm 3,5 \%)$, чем аденогенном $(52,5 \pm 4,6 \% \mathrm{p}=0,048, \mathrm{OP}=1,387,95 \%$ ДИ 0,982-1,846) и особенно крупноклеточном $(45,5 \pm 7,7 \%, p=0,008, O P=1,840$, 95\%ДИ 1,168-2,767).

Прогрессирование заболевания в группе радикально оперированных при T1-4NOMO (n=559) выявлено у $26,6 \%$ больных. Внутригрудной рецидив диагностирован у $12,1 \%$, отдаленный метастаз - у $12,8 \%$ и их сочетание у $1,6 \%$. Отмечена тенденция к увеличению случаев прогрессирования НМРЛ при локализации в верхних долях легких, по отношению к нижним: $29,6 \%$ и 19,7\% соответственно ( $\mathrm{t} \geq 1,95, \mathrm{P}=0,030, \mathrm{OR}=0,599,95 \% \mathrm{Cl}$ 0,377-0,952). По данным многофакторного анализа худший прогноз выявлен у больных крупноклеточным (прогрессирование у $47,4 \pm 7,5 \%, p<0,001$ OP=4,336, 95\%ДИ 2,139-8,791) и аденогенным $(34,4 \pm 3,9 \%, p<0,001,0 P=2,543,95 \% Д и$

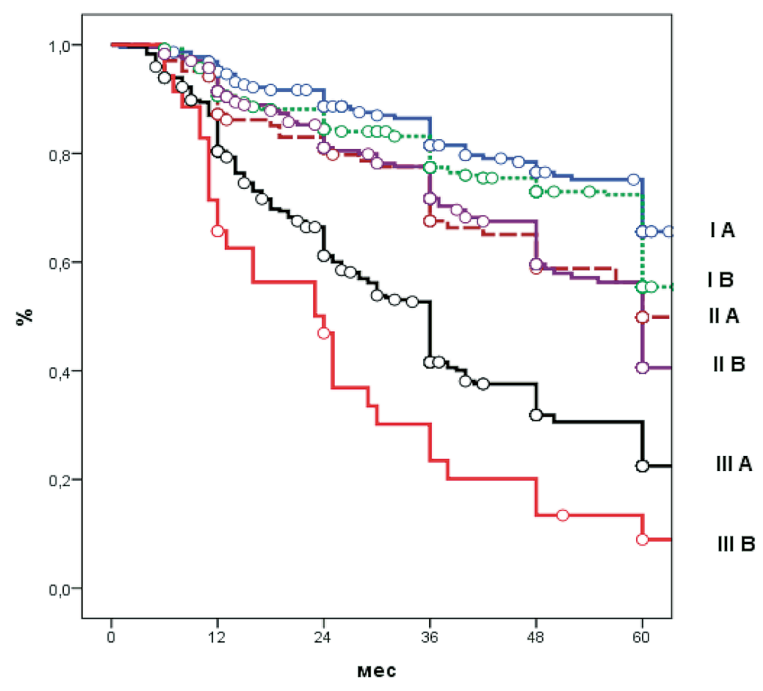

Рисунок 1. Отдаленные результаты хирургического и комбинированного лечения больных НМРЛ с учетом стадии

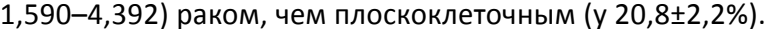

Общая пятилетняя выживаемость 608 больных НМРл $(\mathrm{N}+)$ после радикального комбинированного лечения

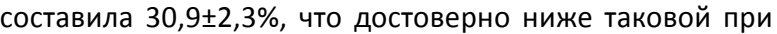
NO $(p<0,05)$. В отличие от пациентов с NO величина опухоли оказывала влияние на результаты: при Т1 более

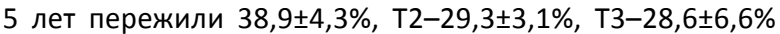

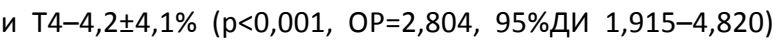
пациентов.

В группе больных с внутригрудными метастазами получены более высокие показатели отдаленных результатов у больных при N1, нежели N2 как в целом $(39,60 \pm 3,0 \%$ и 16,6 $\pm 2,5 \%$ p<0,001, ОР=5,358, 95\%ДИ 3,084-9,306), так и с учетом величины опухоли (рис. 2). Более 5 лет пере-

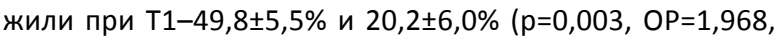

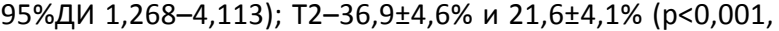
$\mathrm{OP}=2,025,95 \%$ И 1,513-2,720); Т3 $-40,8 \pm 5,0 \%$ и $21,2 \pm 7,4 \%$ $(p=0,001, O P=3,396,95 \% Д И ~ 1,702-6,779)$ и Т4-0\% и 8,3\% ( $p>0,05)$ больных соответственно.

К неблагоприятным факторам выживаемости больных с N+ можно отнести крупноклеточный рак $(p<0,001$, $\mathrm{OP}=2,131)$ и объем операции - билобэктомия $(p=0,007$,

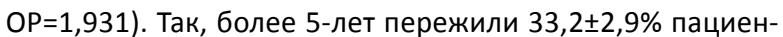
тов плоскоклеточным раком, $33,7 \pm 4,8 \%$ - аденокарцино-

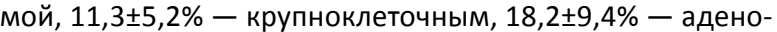

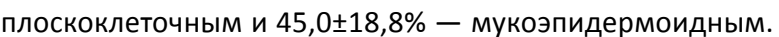
у больных, перенесших пневмонэктомию, одноименный показатель выше $(25,1 \pm 3,1 \%)$, чем билобэктомию $(14,7 \pm 7,1 \%)$, но ниже, чем лобэктомию $(38,8 \pm 3,5 \%)$.

При метастазах в средостенных лимфатических узлах (N2) отдаленные результаты лечения были достоверно выше при поражении одной анатомической зоны $(26,5 \pm 4,3 \%)$, чем нескольких $(14,5 \pm 4,5 \%, p<=0,001$, $\mathrm{OP}=1,829,95 \% Д И ~ 1,391-2,670)$ или всех $(0 \%, p=0,001$, $\mathrm{OP}=2,435,95 \% Д И ~ 1,675-6,607)$.

В группе радикального комбинированного лечения с адъювантной лучевой терапией (T1-4N1-2M0, n=608) прогрессирование заболевания зафиксировано у 50,9\% пациентов: внутригрудной рецидив - у 18,2\%, отдаленный метастаз - у 28,9\% и их сочетание - у 3,7\% больных. При многофакторном анализе подтверждена зависимость прогрессирования НМРЛ от характера и уровня поражения лимфатических узлов (N1- 39,2 22,6\%, N2$65,3 \pm 2,8 \%, p=0,000,0 P=2,770,95 \% Д И ~ 2,019-4,034)$, вели-

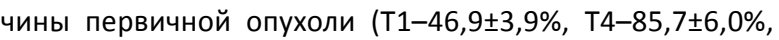
$\mathrm{p}=0,001, \mathrm{OP}=6,637,95 \% Д И$ 2,244-21,221) и ее морфологического типа (плоскоклеточный рак $-47,2 \pm 2,5 \%$, крупноклеточный $-78,2 \pm 6,0 \%, p=0,001, O P=4,128,95 \% Д И$ 1,767-8,049).

Отдаленные результаты у больных с паллиативным лечением также разноречивы, так у больных получавших дополнительную лучевую терапия $(\mathrm{n}=64)$ после нерадикальной операции пятилетняя выживаемость составила $29,6 \pm 7,1 \%$, не получавших $(n=36)-10,5 \pm 6,6 \%$. У пациентов после радикальных операций, но не получивших дополнительное противоопухолевое лечение при $\mathrm{N}+$

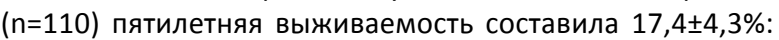

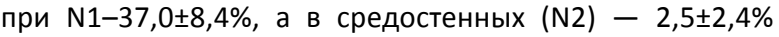
$(\mathrm{P}=0,045, \mathrm{OR}=4,404,95 \% \mathrm{Cl} 2,373-8,567)$. 


\section{Обсуждение и выводы}

Отдаленные результаты хирургического лечения у больных без метастазов в регионарных лимфатических узлах при IА стадии (T1NOMO) колеблются от $63 \%$ до $80 \%$ $[10,11]$, IB (T2NOMO) от 44\% до 72\% $[12,11]$ и IIB (T3NOMO) от $35 \%$ до 43,9\% [13, 14]. Разброс показателей в пределах даже одной стадии может быть обусловлен неоднородностью групп больных как в пределах символа «Т» по международной классификации TNM шестого пересмотра, так и с учетом морфологического типа НМРЛ. Врастание опухоли в соседние структуры снижает результаты лечения, приближая их к таковым у больных при Т1-2N1 M0, составляя 32-52\% [10,15]. Независимым прогностическим фактором в данной группе больных может оказаться уровень поражения лимфатических узлов: при метастазах только в бронхопульмональных узлах более 5-ти лет переживает 53-64\%, а в бронхопульмональных и корневых уже $21-49 \%[16,17]$.
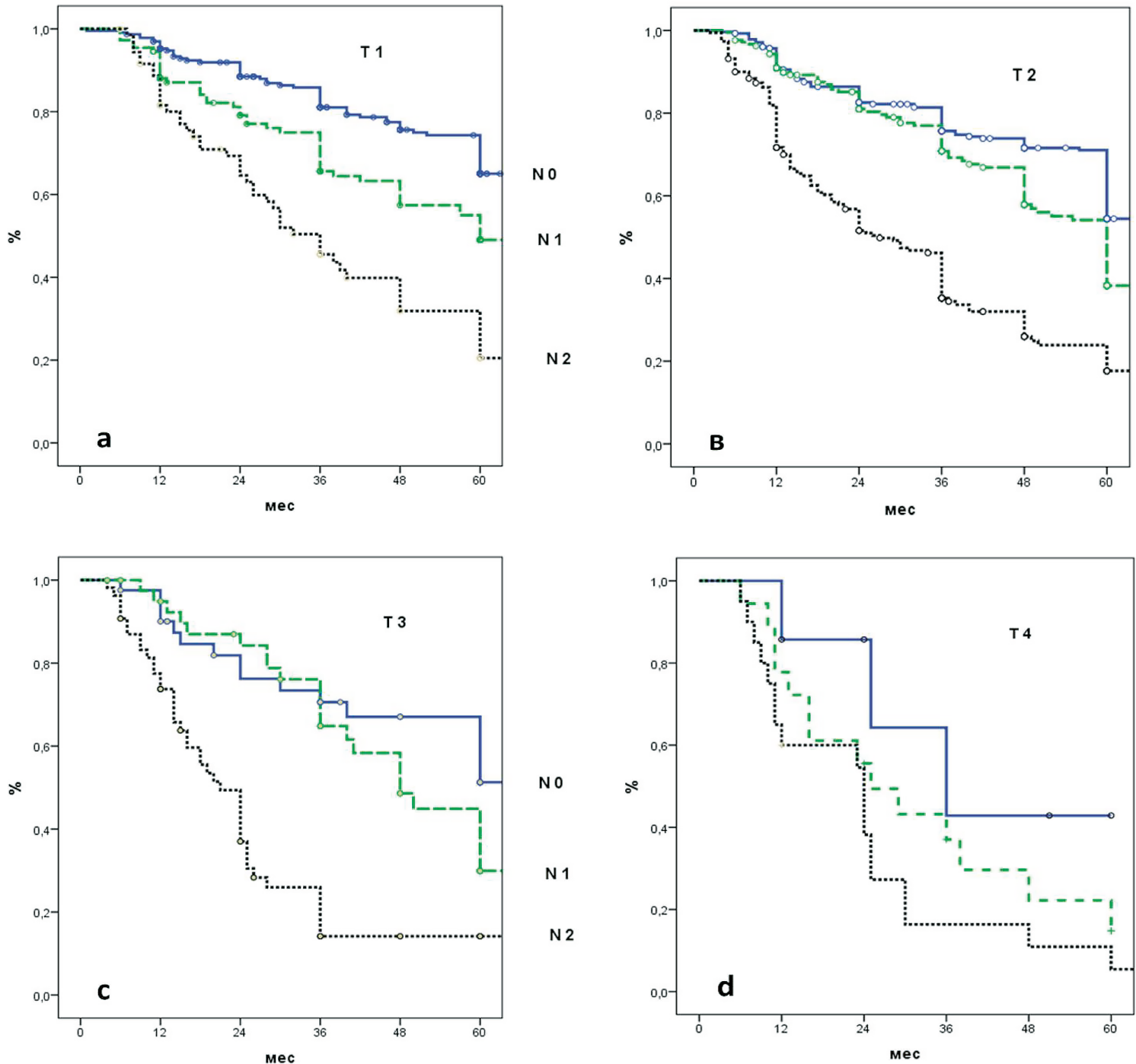
дикторов отдаленных результатов лечения. По данным Okada M. с соавт. (2005), лучшие показатели хирургического лечения больных НMPJ получены при метастазах в узлах N1 нежели N2 (50,8\%, 16,7\% соответственно) [18].

Отмечается существенный разброс (9-35\%) показателей хирургического (комбинированного) лечения больных НМРЛ с метастазами в средостенных узлах $[19,20,21]$.

При углубленном анализа выживаемости группы больных с $\mathrm{N}+$ установлено, что при поражении внутрилегочных узлов пятилетняя выживаемость составила $60,1 \%$, внутрилегочных и корневых - 38,8\%, нижних средостенных - 24,8\%, верхних - 0\% [18]. Некоторые исследователи проводят количественную оценку пораженных средостенных лимфатических узлов, что по их мнению коррелирует с отдаленными результатами. При метастазах в одном узле более 5 лет переживают 41,6\% больных, двух и более - 35,3\% и 0\% соответственно, при

Рисунок 2. Отдаленные результаты радикального лечения больных НМРЛ с учетом величины опухоли и характера регионарного метастазирования: а-T1, в-T2, с-T3, d-T4.

No

N 1

N 2 
этом общая выживаемость составляет 25,0\% [22]. Другие исследователи поддерживают суждение о снижении показателей лечения с учетом зональности поражения средостенных лимфатических узлов. Так, при метастазах уже в верхних паратрахеальных узлах выживаемость снижается в два раза [23], а при массивном поражении всех групп составляет только 2\% [24]

Применение лучевой терапии в адьювантном режиме у больных НМРЛ с метастазами в лимфатических узлах позволяет добиться удовлетворительных результатов [5]. Многие исследователи едины во мнении, что при N1 не наблюдается увеличения продолжительности жизни [25], а при N2 отмечено достоверное снижение частоты местного рецидива $[20,26]$. По данным Matsuguma H. с соавт. (2012), пятилетняя общая выживаемость при послеоперационной лучевой терапии у больных с N2 составила 53,2\% (группа 1), а только хирургическом лечении (группа 2) - 27,5\% (p=0,628) [7]. При этом показатель безрецидивной выживаемости у больных в первой группе был достоверно выше, чем во второй: $41 \%$ и 5,9\% соответственно. Следует отметить, что, несмотря на радикальное лечение, у 54,3\% больных с N2 диагностируют отдаленные метастазы: при комбинированном - у 49,0\%, при хирургическом - у 66,4\%.

При использовании полихимиотерапии в адъювантном режиме получено статистически достоверное увеличение общей и безрецидивной пятилетней выживаемости по сравнению с только хирургическим лечением у больных НМРЛ (N1-2) на 4,1\% (44,5\% против 40,4\%, p =0,03) и 5,1\% (39,4 против 34,3\%, p = 0,03) соответственно [27].

Применение неоадъювантной химиотерапии (HAXT) позволяет добиться $46 \%$ пятилетней выживаемости у больных НМРЛ III стадии. К неблагоприятным факторам следует отнести неудовлетворительный (менее 50\%) непосредственный клинический эффект и множественные метастазы в средостенных узлах [4]. Однако, при достижении пятилетнего рубежа у 60\% больных с НАХT диагностируют местный рецидив, а у 65\% - отдаленные метастазы [28].

Трехкомпонентное лечение с последовательным

\section{Информация о соавторах:}

1. Трахтенберг Александр Хунович, доктор медицинских наук, профессор, главный научный сотрудник торакального отделения отдела торакоабдоминальной онкохирургии МНИОИ им. П. А. Герцена - филиал ФГБУ «ФМИЦ им. П. А. Герцена» Минздрава России

2. Пикин Олег Валентинович, доктор медицинских наук, руководитель торакального отделения отдела торакоабдоминальной онкохирургии МНИОИ им. П. А. Герцена - филиал ФГБУ «ФМИЦ им. П. А. Герцена» Минздрава России

3. Рябов Андрей Борисович, доктор медицинских наук, руководитель отдела торакоабдоминальной онкохирургии МНИОИ им. П.А. Герцена - филиал ФГБУ «ФМИЦ им. П. А. Герцена» Минздрава России

4. Глушко Владимир Алексеевич, доктор медицинских наук, старший научный сотрудник торакального отделения отдела торакоабдоминальной онкохирургии МНИОИ им. П. А. Герцена - филиал ФГБУ «ФМИЦ им. П. А. Герцена» Минздрава России. применением химиолучевой терапии (2 курса платиносодержащими схемами и лучевая терапия СОД 40-46 Гр) и радикальной операцией позволило достичь $60 \%$ общей пятилетней и 57\% безрецидивной двухлетней выживаемости у больных с метастазами в средостенных узлах [29].

\section{Заключение}

Радикальное хирургическое и комбинированное лечение может быть проведено большинству больных резектабельным немелкоклеточным раком легкого с удовлетворительными отдаленными результатами. Показатели пятилетней выживаемости в два раза выше при радикальном лечении, чем паллиативном в целом, что позволяет считать характер лечения одним из основных факторов прогноза.

При радикальном лечении стадия заболевания играет существенную роль в выживаемости. При отсутствии метастазов в регионарных лимфатических узлах величина первичной опухоли существенно не оказывает прогностического влияния, значимым неблагоприятным фактором следует считать аденогенный и особенно крупноклеточный морфологический тип рака. Наличие метастазов во внутригрудных узлах ухудшает прогноз. При поражении узлов группы N1 отдаленные показатели достоверно хуже у больных с величиной опухоли Т4 и крупноклеточном раке, а N2 - с метастазами в нескольких и всех зонах средостения и объеме операции билобэктомия.

Применение послеоперационной лучевой терапией при N2 позволяет добиться удовлетворительных отдаленных результатов комбинированного лечения больных HMPJ. Учитывая крайне низкие показатели выживаемости при множественных метастазах в средостенных узлах целесообразно более тщательное дооперационное стадирование по символу N2, неоадьювантное или трехкомпонентное противоопухолевое лечение. Частота отдаленных метастазов после радикального лечения особенно при N2 заставляет шире использовать лекарственный компонент противоопухолевого воздействия в комбинированном лечении.

Information about co-authors:

1. Trakhtenberg Aleksandr Hunovich, MD, professor, major researcher of thoracic department of thoracoabdominal division Moscow Oncology Institute of the Hertsen FMRC MH RF

2. Pikin Oleg Valentinovich, MD, head of thoracic department of thoracoabdominal division Moscow Oncology Institute of the Hertsen FMRC MH RF

3. Rjabov Andrej Borisovich, MD, head of thoracoabdominal division Moscow Oncology Institute of the Hertsen FMRC MH RF

4. Glushko Vladimir Alekseevich, senior researcher of thoracic department of thoracoabdominal division Moscow Oncology Institute of the Hertsen FMRC MH RFП. А. Герцена филиал ФГБУ «ФМИЦ им. П. А. Герцена» Минздрава России 
Список литературы:

1. Под ред. А.Д. Каприна В.В. Старинского, Г.В. Петровой Состояние онкологической помощи населению России в 2013 году [Книга]. - М : ФГБУ «МНИОИ им. П.А. Герцена» Минздрава России, 2014. - стр. 235.

2. Трахтенберг А.Х., Колбанов К. И. Рак легкого [Book]. - М : Геотар Медиа, 2012. - р. 160.

3. Crino L., Weder W., van Meerbeeck J., Felip E. Клинические peкомендации ESMO по диагностике, лечению и наблюдению при начальных и местнораспространенных стадиях немелкоклеточного рака легкого (НМРЛ).Минимальные клинические рекомендации европейского общества медицинской онкологии (ESMO) [Книга] / перев. Перевод с англ. Москва, РОНЦ им Н.Н.Блохина. - М : РОНЦ им Н.Н.Блохина, 2010.

4. Carretta A., Ciriaco P., Melloni G., Sayed I. Results of surgical treatment after neoadjuvant chemotherapy for stage III nonsmall cell lung cancer [Journal] // World J Surg. - 2008. - Vol. 32. - pp. 2636-42.

5. Scotti V., Meattini I., Saieva C. et al. Post-operative radiotherapy in N2 non-small cell lung cancer: a retrospective analysis of 175 patients [Journal] // Radiother Oncol. - 2010. - Vol. 96. - pp. 84-8.

6. Zhang X., Zhang B., Gao Y. Clinical application of adjuvant treatment after operation in patients with stage Illa non-small cell lung cancer [Journal] // Zhongguo Fei Ai Za Zhi. - 2010. - Vol. 13. - pp. 357-62

7. Matsuguma H., Oki I., Nakahara R. et al. Proposal of new nodal classifications for non-small-cell lung cancer bas $3 \mathrm{~d}$ on the number and ratio of metastatic lymph nodes [Journal] // Eur J Cardiothorac Surg. - 2012. - Vol. 41. - pp. 19-24.

8. Волков С.М. Оценка эффективности и пути совершенствования хирургии немелкоклеточного рака легкого // Автореф. дис. ...... док. мед. наук. - М : [б.н.], 2005 г. - стр. 48.

9. Харченко В.П., Хмелевский Е.В. Комбинированное и хирургическое лечение рака легкого [Конференция] // Материалы VI всероссийского съезда онкологов. - Ростов-на-Дону : [б.н.], 2005. - Т. 1. - стр. 345.

10. Van Rens M.T., de la Riviere A.B., Elbers H.R., van Den Bosch J.M. Prognostic assessment of 2,361 patients who underwent pulmonary resection for non-small cell lung cancer, stage I, II, and IIIA [Journal] // Chest. - 2000. - Vol. 117. - pp. 374-379.

11. Cerfolio R.J., Bryant A.S. Survival of patients with true pathologic stage I non-small cell lung cancer [Journal] // nn Thorac Surg. 2009. - Vol. 88. - pp. 917-22.

12. Garcia-Yuste M., Matilla J.M., Duque J.L. et al. Surgical treatment of lung cancer: comparative assessment of the staging systems of 1986 and 1997. Results in 500 consecutive patients [Journal] // Arch Bronconeumol. - 2001. - Vol. 37. - p. 54.

13. Hayashi Y., Tomiyama I., Ishii H. et al. Prognostic assessment of the new UICC TNM classification for resected lung cancer [Journal] // Kyobu Geka. - 2000. - Vol. 53. - pp. 919-25.

14. Saito Y., Yamakawa Y., Kuriyama M. et al. Evaluation of new TNM lung cancer classification [Journal] // J Thorac Cardiovasc Surg. - 2000. - Vol. 48. - pp. 499-505.

15. Gonfiotti A., Crocetti E., Lopes Pegna A. et al. Prognostic variability in completely resected pN1 non-small-cell lung cancer [Journal] // Asian Cardiovasc Thorac Ann. - 2008. - Vol. 16. - pp. $375-80$.

16. Caldarella A., Crocetti E., Comin C.E. et al. Prognostic variability among nonsmall cell lung cancer patients with pathologic N1 lymph node involvement. Epidemiological figures with strong clinical implication [Journal] // Cance. - 2006. - Vol. 107. - pp. 793-8.
17. Shimada Y., Tsuboi M., Saji H. et al. The prognostic impact of main bronchial lymph node involvement in non-small cell lung carcinoma: suggestions for a modification of the staging system [Journal] // Ann Thorac Surg. - 2009. - Vol. 88. - pp. 1583-8.

18. Okada M., Sakamoto T., Yuki T. et al. Border between N1 and N2 stations in lung carcinoma: lessons from lymph node metastatic patterns of lower lobe tumors [Journal] // J Thorac Cardiovasc Surg. - 2005. - Vol. 129. - p. 825.

19. Cerfolio R.J., Bryant A.S. Survival of patients with unsuspected N2 (stage IIIA) nonsmall-cell lung cancer [Journal] // Ann Thorac Surg. - 2008. - Vol. 86. - pp. 362-6; discussion 366-7.

20. Ma Q., Liu D., Guo Y. et al. Surgical therapeutic strategy for nonsmall cell lung cancer with mediastinal lymph node metastasis (N2) [Journal] // Zhongguo Fei Ai Za Zhi. - 2010. - Vol. 13. - pp. 342-8.

21. Meacci E., Cesario A., Cusumano G. et al. Surgery for patients with persistent pathological N2 IIIA stage in non-small-cell lung cancer after induction radio-chemotherapy: the microscopic seed of doubt [Journal] // Eur J Cardiothorac Surg. - 2011. - Vol. 40. - pp. 656-63.

22. Tanaka F., Yanagihara K., Otake Y. et al. Prognostic factors in resected pathologic ( $p$-) stage IIIA-N2, non-small-cell lung cancer [Journal] // Ann Surg Oncol. - 2004. - Vol. 11. - pp. 612-8.

23. Sakao Y., Miyamoto H., Yamazaki A. et al. Prognostic significance of metastasis to the highest mediastinal lymph node in nonsmall cell lung cancer [Journal] // Ann Thorac Sur. - 2006. Vol. 81. - pp. 292-7.

24. Gawrychowski J., Gabriel A., Lackowska B. Heterogeneity of stage IIIA non-small cell lung cancers (NSCLC) and evaluation of late results of surgical treatment [Journal] // Eur J Surg Oncol. 2003. - Vol. 29. - pp. 78-84.

25. Lally B.E., Zelterman D., Colasanto J.M. et al. Postoperative radiotherapy for stage II or III non-small-cell lung cancer using the Surveillance, Epidemiology, and End Results database [Journal] // J Clin Oncol. - 2006. - Vol. 24. - pp. 2998-3006.

26. Spoelstra F.O, Senan S, Le Pechoux C. et al. Lung Adjuvant Radiotherapy Trial Investigators Group. Variations in target volume definition for postoperative radiotherapy in stage III non-small-cell lung cancer: Analysis of an international contouring study [Journal] // Int J Radiat Oncol Biol Phys. 2010. - Vol. 76. - pp. 1106-1113.

27. Le Chevalier T., Dunant A., Arriadada R. et al. Long-term results of the Internacional Adjuvant Lung Cancer Trial (IALT) evaluating adjuvant cisplatin-based chemotherapy in resected non-small cell cancer [Journal] // J Clin Oncol. - 2008. - Vol. 26. p. 398 (abstr 7507).

28. Betticher D.C., Hsu Schmitz S.F., Tötsch M. et al. Prognostic factors affecting long-term outcomes in patients with resected stage IIIA pN2 non-small-cell lung cancer: 5-year follow-up of a phase II study [Journal] // Br J Cancer. - 2006. - Vol. 94. - pp. 1099-106.

29. Toyooka S., Kiura K., Shien K. et al. Induction chemoradiotherapy is superior to induction chemotherapy for the survival of nonsmall-cell lung cancer patients with pathological mediastinal lymph node metastasis [Journal] // Cardio Vase Thorac Surg. 2012. - pp. 954-960. 
References:

1. Pod red. Kaprina A.D., Starinskogo V.V., Petrovoj G.V. Sostojanie onkologicheskoj pomoshhi naseleniju Rossii v 2013 godu [Kniga]. - M : FGBU «MNIOI im. P.A. Gercena» Minzdrava Rossii, 2014. - str. 235.

2. Trahtenberg A.H., Kolbanov K. I. Rak legkogo [Book]. - M : Geotar Media, 2012. - p. 160.

3. Crino L., Weder W., van Meerbeeck J., Felip E. Klinicheskie rekomendacii ESMO po diagnostike, lecheniju i nabljudeniju pri nachal'nyh i mestnorasprostranennyh stadijah nemelkokletochnogo raka legkogo (NMRL).Minimal'nye klinicheskie rekomendacii evropejskogo obshhestva medicinskoj onkologii (ESMO) [Kniga] / perev. Perevod s angl. Moskva, RONC im N.N.Blohina. - M : RONC im N.N.Blohina, 2010.

4. Carretta A., Ciriaco P., Melloni G., Sayed I. Results of surgical treatment after neoadjuvant chemotherapy for stage III nonsmall cell lung cancer [Journal] // World J Surg. - 2008. - Vol. 32. - pp. 2636-42.

5. Scotti V., Meattini I., Saieva C. et al. Post-operative radiotherapy in N2 non-small cell lung cancer: a retrospective analysis of 175 patients [Journal] // Radiother Oncol. - 2010. - Vol. 96. - pp. 84-8.

6. Zhang X., Zhang B., Gao Y. Clinical application of adjuvant treatment after operation in patients with stage IIla non-small cell lung cancer [Journal] // Zhongguo Fei Ai Za Zhi. - 2010. - Vol. 13. - pp. 357-62.

7. Matsuguma H., Oki I., Nakahara R. et al. Proposal of new nodal classifications for non-small-cell lung cancer bas $3 d$ on the number and ratio of metastatic lymph nodes [Journal] // Eur J Cardiothorac Surg. - 2012. - Vol. 41. - pp. 19-24.

8. Volkov S.M. Ocenka jeffektivnosti i puti sovershenstvovanija hirurgii nemelkokletochnogo raka legkogo // Avtoref. dis. ...... dok. med. nauk. - M : [b.n.], 2005 g. - str. 48.

9. Harchenko V.P., Hmelevskij E.V. Kombinirovannoe i hirurgicheskoe lechenie raka legkogo [Konferencija] // Materialy VI vserossijskogo s\#ezda onkologov. - Rostov-naDonu : [b.n.], 2005. - T. 1. - str. 345.

10. Van Rens M.T., de la Riviere A.B., Elbers H.R., van Den Bosch J.M. Prognostic assessment of 2,361 patients who underwent pulmonary resection for non-small cell lung cancer, stage I, II, and IIIA [Journal] // Chest. - 2000. - Vol. 117. - pp. 374-379.

11. Cerfolio R.J., Bryant A.S. Survival of patients with true pathologic stage I non-small cell lung cancer [Journal] // nn Thorac Surg. 2009. - Vol. 88. - pp. 917-22.

12. Garcia-Yuste M., Matilla J.M., Duque J.L. et al. Surgical treatment of lung cancer: comparative assessment of the staging systems of 1986 and 1997. Results in 500 consecutive patients [Journal] // Arch Bronconeumol. - 2001. - Vol. 37. - p. 54.

13. Hayashi Y., Tomiyama I., Ishii H. et al. Prognostic assessment of the new UICC TNM classification for resected lung cancer [Journal] // Kyobu Geka. - 2000. - Vol. 53. - pp. 919-25.

14. Saito Y., Yamakawa Y., Kuriyama M. et al. Evaluation of new TNM lung cancer classification [Journal] // J Thorac Cardiovasc Surg. - 2000. - Vol. 48. - pp. 499-505.

15. Gonfiotti A., Crocetti E., Lopes Pegna A. et al. Prognostic variability in completely resected pN1 non-small-cell lung cancer [Journal] // Asian Cardiovasc Thorac Ann. - 2008. - Vol. 16. - pp. $375-80$

16. Caldarella A., Crocetti E., Comin C.E. et al. Prognostic variability among nonsmall cell lung cancer patients with pathologic N1 lymph node involvement. Epidemiological figures with strong clinical implication [Journal] // Cance. - 2006. - Vol. 107. - pp. 793-8.
17. Shimada Y., Tsuboi M., Saji H. et al. The prognostic impact of main bronchial lymph node involvement in non-small cell lung carcinoma: suggestions for a modification of the staging system [Journal] // Ann Thorac Surg. - 2009. - Vol. 88. - pp. 1583-8.

18. Okada M., Sakamoto T., Yuki T. et al. Border between N1 and N2 stations in lung carcinoma: lessons from lymph node metastatic patterns of lower lobe tumors [Journal] // J Thorac Cardiovasc Surg. - 2005. - Vol. 129. - p. 825.

19. Cerfolio R.J., Bryant A.S. Survival of patients with unsuspected N2 (stage IIIA) nonsmall-cell lung cancer [Journal] // Ann Thorac Surg. - 2008. - Vol. 86. - pp. 362-6; discussion 366-7.

20. 20. Ma Q., Liu D., Guo Y. et al. Surgical therapeutic strategy for non-small cell lung cancer with mediastinal lymph node metastasis (N2) [Journal] // Zhongguo Fei Ai Za Zhi. - 2010. Vol. 13. - pp. 342-8.

21. Meacci E., Cesario A., Cusumano G. et al. Surgery for patients with persistent pathological N2 IIIA stage in non-small-cell lung cancer after induction radio-chemotherapy: the microscopic seed of doubt [Journal] // Eur J Cardiothorac Surg. - 2011. - Vol. 40. - pp. 656-63.

22. Tanaka F., Yanagihara K., Otake Y. et al. Prognostic factors in resected pathologic ( $\mathrm{p}-$ ) stage IIIA-N2, non-small-cell lung cancer [Journal] // Ann Surg Oncol. - 2004. - Vol. 11. - pp. 612-8.

23. Sakao Y., Miyamoto H., Yamazaki A. et al. Prognostic significance of metastasis to the highest mediastinal lymph node in nonsmall cell lung cancer [Journal] // Ann Thorac Sur. - 2006. - Vol. 81. - pp. 292-7.

24. Gawrychowski J., Gabriel A., Lackowska B. Heterogeneity of stage IIIA non-small cell lung cancers (NSCLC) and evaluation of late gesults of surgical treatment [Journal] // Eur J Surg Oncol. - 2003. - Vol. 29. - pp. 78-84.

25. Lally V.E., Zelterman D., Colasanto J.M. et al. Postoperative radiotherapy for stage II or III non-small-cell lung cancer using the Surveillance, Epidemiology, and End Results database [Journal] // J Clin Oncol. - 2006. - Vol. 24. - pp. 2998-3006.

26. Spoelstra F.O, Senan S, Le Pechoux C. et al. Lung Adjuvant Radiotherapy Trial Investigators Group. Variations in target volume definition for postoperative radiotherapy in stage III non-small-cell lung cancer: Analysis of an international contouring study [Journal] // Int J Radiat Oncol Biol Phys. 2010. - Vol. 76. - pp. 1106-1113.

27. Le Chevalier T., Dunant A., Arriadada R. et al. Long-term results of the Internacional Adjuvant Lung Cancer Trial (IALT) evaluating adjuvant cisplatin-based chemotherapy in resected non-small cell cancer [Journal] // J Clin Oncol. - 2008. - Vol. 26. - p. 398 (abstr 7507).

28. Betticher D.C., Hsu Schmitz S.F., Tötsch M. et al. Prognostic factors affecting long-term outcomes in patients with resected stage IIIA pN2 non-small-cell lung cancer: 5-year follow-up of a phase II study [Journal] // Br J Cancer. - 2006. - Vol. 94. - pp. 1099-106

29. Toyooka S., Kiura K., Shien K. et al. Induction chemoradiotherapy is superior to induction chemotherapy for the survival of nonsmall-cell lung cancer patients with pathological mediastinal lymph node metastasis [Journal] // Cardio Vase Thorac Surg. - 2012. - pp. 954-960. 